\title{
MARCHA RUMO À AMAZÔNIA: A RELAÇÃO CRIADOR/CRIATURA NO DISCURSO DE FUNDAÇÃO DA GLEBA CELESTE, EM MATO GROSSO
}

\section{MARCHING TOWARDS THE AMAZON: THE CREATOR/CREATURE RELATIONSHIP IN THE DISCOURSE OF FUNDATION OF THE GLEBA CELESTE, IN MATO GROSSO}

\author{
Leandro José do Nascimento ${ }^{1}$, Fernando Zolin-Vesz ${ }^{2}$
}

\begin{abstract}
RESUMO: A década de setenta marca, na região norte de Mato Grosso, o surgimento do projeto de colonização Gleba Celeste. Nele, a Colonizadora SINOP S.A., dos empresários Enio Pipino e João Pedro Moreira de Carvalho, implanta as cidades de Vera, Sinop, Santa Carmem e Cláudia. Este artigo analisa o discurso da fundação da Gleba Celeste a fim de observar os efeitos produzidos e como reafirmam a lógica criador/criatura. $O$ estudo do discurso recorre à entrevista de Enio Pipino ao Museu da Imagem e do Som (1982), por meio da qual a narrativa de colonização é realizada. A análise é amparada em conceitos como formação discursiva, enunciado, relações de poder, verdade e poder inscritos em Michel Foucault e sugere que a fundação deste empreendimento não correspondeu, apenas, como uma estratégia administrativa de criação de cidades, mas um esforço para levar a verdade a outrem, evidenciando uma hierarquia no/pelo discurso.
\end{abstract}

PALAVRAS-CHAVE Gleba Celeste; Mato Grosso; discurso da fundação

\begin{abstract}
The 70ths mark, in the northern region of Mato Grosso, the appearance of the colonization project Gleba Celeste. In it, Colonizadora SINOP S.A., of entrepreneurs Enio Pipino and João Pedro Moreira de Carvalho, deploys the cities of Vera, Sinop, Santa Carmem and Cláudia. This article analyzes the discourse of the foundation of Gleba Celeste in order to observe the effects produced and how they reaffirm the creator/creature logic. The discourse study uses Enio Pipino's interview granted to the Museum of Image and Sound (1982), through which the colonization narrative is carried out. The analysis is supported by concepts such as discursive formation, enunciated, relations of power, truth and power inscribed in Michel Foucault and suggests that the foundation of this undertaking did not correspond only as an administrative strategy of creating cities, but an effort to lead to the truth to others, showing a hierarchy in/by discourse.
\end{abstract}

KEY-WORDS: Gleba Celeste, Mato Grosso, discourse of foundation

\section{Introdução}

\footnotetext{
${ }^{1}$ Doutorando no PPG em Estudos de Linguagem da UFMT.

${ }^{2}$ Doutor em Letras e Linguística pela UFG. Professor do Departamento de Letras e do PPG em Estudos de Linguagem da UFMT.
} 
As práticas discursivas idealizadas em torno do projeto de ocupação da Amazônia Brasileira, a partir da década de 1970, mais que fundar sentidos sobre esse espaço geográfico pouco ou nada explorado à época, atuaram na construção de um imaginário local. Em voga, muitas dessas práticas discursivas procuraram significar as áreas não como imensas faixas de terra com mata fechada, inóspitas, repletas de desafios e perigos, mas locais de sonhos, de "promessa de terra fértil, de um clima bom e sem geadas, promessa de um lugar ideal onde o colono sulista poderia sonhar em um dia tornar-se grande fazendeiro e seus filhos teriam um futuro melhor que aquele que os pais tiveram no passado" (ROHDEN, 2012, p. 178).

No centro está o fazer ocupar e justificar tais operações, convidando o migrante a “ingressar numa 'aventura' rumo à 'Selva Amazônica' em busca de um 'mundo novo', da "Terra Prometida'” (ROHDEN, 2012, p. 178). No contexto da instituição dos projetos de colonização na Amazônia brasileira coincide o período de fundação da Gleba Celeste, situada na parte Norte do Estado de Mato Grosso, e a partir da qual foram fundadas quatro cidades: Vera, em 1972, Sinop e Santa Carmem em 1974, e Cláudia, em 1978. Neste interim, muitos dos indivíduos que partiram em direção à Amazônia Legal, nos idos de 1970, levariam "projetos de uma vida com fartura em terras desconhecidas e supostamente cheias de riquezas. Um lugar do 'café sem geada' onde existiria muita terra para seus filhos juntos" (ARRUDA, 1997, p. 88).

Propriedade da empresa Colonizadora Sociedade Imobiliária Noroeste do Paraná (Sinop S/A), a Gleba Celeste correspondia a uma faixa de terra com mais de 645 mil hectares e para a qual foram atraídas dezenas de migrantes, a maior parte da região Sul do país. A partir de um trabalho de ampla divulgação realizada em jornais e anúncios publicitários, para o local buscavam-se pessoas dispostas à realizarem a ocupação da Amazônia de forma ordenada, isto é, "gente de primeira grandeza, bons produtores, bons agricultores, homens ordeiros, populações orientadas", conforme descrevia o próprio empresário paulista Enio Pipino em uma referência ao perfil do migrante ideal à colonização.

Em meio às estratégias econômicas implementadas com o propósito de promovê-la, no/pelo discurso, a Gleba Celeste foi sendo significada. Seja pelo governamental, o empresarial, o jornalístico, publicitário ou mesmo aquele que emanou dos próprios agentes envolvidos no processo (os colonizadores), o espaço tornou-se objeto de práticas discursivas capazes de significar bem como construir o mundo social ao seu redor. 
Partindo do apontamento de Fabrício (2006, p. 55) de que os "discursos configuram ambientes, produzem espaços e criam noções de coerência e estabilidade", portando-se como um efeito, “uma operação de práticas discursivas 'ordenadoras' do mundo social, denominada lógica efeito-instrumento" (FABRÍCIO, 2006, p. 55) é que a presente investigação é proposta. Busca-se compreender como, face à implementação e abertura da Gleba Celeste, o discurso do colonizador Enio Pipino produz sentidos sobre esta área e atua na produção de efeitos de verdade (FOUCAULT, 2008; 2018), ao mesmo tempo em que acentua a existência de duas categorias inerentes ao processo: o criador e a criatura.

A pesquisa ampara-se em um estudo discursivo não restrito à ótica materialista do texto, aos elementos linguísticos que o constitui. O discurso, que pela acepção foucaultiana passa a ser entendido como prática social, construindo sentidos que, em seus efeitos, parecem "reais" - e, por parecerem "reais", têm efeito de verdade (FOUCAULT, 2018), constitui o objeto da análise. Em Foucault (2008), o discurso é um conjunto de sequências de signos por exemplo, uma frase, uma proposição ou um ato de linguagem, orais ou escritos -, enquanto enunciados, que, em determinadas condições, possuem uma existência específica no jogo enunciativo. Isto é, o discurso "é o conjunto de enunciados que se apoia em um mesmo sistema de formação" (FOUCAULT, 2008, p. 122), produzido em decorrência das relações de poder.

Este artigo está organizado em três partes. Na primeira delas, o processo sóciohistórico de constituição do projeto de colonização às margens da BR-163 é apresentado. A etapa possibilita compreender a ligação entre tal iniciativa e as práticas discursivas, uma vez que um ou mais discursos se constroem a partir de dadas condições de produção. O diálogo com autores como Santos (2011), Souza (2006, 2015), Moreno (2005), Teixeira (2006) entre outros, favorece o retorno à formação da Gleba Celeste.

A segunda parte do estudo dedica-se ao discurso, amparando-se nos preceitos de Michel Foucault $(2008,2018)$. O conceito de discurso é apresentado como prática. Segundo Foucault (2018), práticas discursivas criam sentidos que possuem efeito de verdade e, nessa relação, as práticas discursivas do empresário paulista Enio Pipino operam de tal maneira. Busca-se observar o discurso perante a ótica foucaultiana e à luz das noções de formação discursiva, relações de poder, verdade e enunciado.

$\mathrm{Na}$ terceira parte, recorre-se à entrevista concedida pelo colonizador Enio Pipino, em 1982, ao Museu da Imagem e do Som (MIS), de São Paulo, por meio da qual o empresário trata do processo de constituição da Gleba Celeste. A narrativa não é analisada em seu todo - 
53 minutos e 13 segundos de gravação -, mas a partir de enunciados que tomam a fundação da Gleba Celeste sob o espectro do trabalho de divulgação do empreendimento, a atração do sujeito migrante, a finalidade do projeto empresarial e a aventura em meio à Amazônia nortemato-grossense.

\section{A Gleba Celeste na Amazônia brasileira}

A ocupação dos espaços até então pouco habitados na Amazônia Legal brasileira ${ }^{3}$, a partir da década de 1970, marca um período recente da história brasileira e que se encontra fundamentada nas estratégias do Governo Militar. Para transformar a região Centro-Norte do país, na qual ainda se encontravam as terras pouco ou nada exploradas economicamente, o Estado constituiu programas de desenvolvimento regional (TEIXEIRA, 2006) para assegurar acesso a essas regiões, por meio da construção de rodovias de longa distância, além de estimular a criação de polos de desenvolvimento econômico.

Com a elaboração dos Planos Nacionais de Desenvolvimento (PND’s) I e II, diferentes projetos político-econômicos foram formulados com o propósito de acelerar a ocupação de terras, estimular a infraestrutura e a migração. No governo do então presidente Emílio Garrastazu Médici (1969-1974), o I PND (I PND - 1972-1974) foi instituído a partir da Lei número 5.727, de 04 de novembro de 1971, vinculado ao Programa de Integração Nacional (PIN), com a finalidade específica de financiar o plano de obras de infraestrutura nas regiões de atuação da Superintendência de Desenvolvimento da Amazônia (SUDAM) e da Superintendência de Desenvolvimento do Nordeste (SUDENE). Desta forma, promover a integração regional à economia nacional (BRASIL, 1970).

Somente em Mato Grosso, durante o PIN, foram abertas as rodovias federais BR-163, ligando Cuiabá a Santarém, a BR-364 entre Cuiabá e Porto Velho, a BR-070 entre o rio Araguaia e Cuiabá, a BR-080 entre Rio Araguaia e Cachimbo, a BR-158 entre Barra do Garças e São Félix do Araguaia, e a BR-174 entre Cáceres e Rondônia (MORENO, 2005). Nesta conjuntura, como parte do I PND, o Programa de Redistribuição de Terras e de Estímulo à Agroindústria do Norte e Nordeste (PROTERRA) operava no estímulo e fomento ao setor agroindustrial na região da Amazônia Legal brasileira.

\footnotetext{
${ }^{3}$ Compreende o espaço territorial com mais de 5, 2 milhões de quilômetros quadrados de extensão formado por nove estados brasileiros: Acre, Pará, Amazonas, Amapá, Roraima, Rondônia, Mato Grosso a norte do paralelo de $16^{\circ}$, Goiás, a norte do paralelo de $13^{\circ}$, e Maranhão, a oeste do meridiano de $44^{\circ}$, segundo a Lei federal n. 5.173, de 1966. 
Por sua vez, o II PND (1975-1979), no governo de Ernesto Geisel (1974-1979), a partir da Lei número 6.151, de 4 de dezembro de 1974, objetivava a construção de uma política de uso da terra para fins agropecuários com a execução de reforma agrária pelo Instituto Nacional de Reforma e Colonização Agrária (Incra), a partir da "legitimação da posse na faixa dos $100 \mathrm{~km}$ laterais às rodovias federais da Amazônia, e a melhor distribuição de terras nas áreas de tensões” (BRASIL, 1974, p. 43). O II PND propiciou a redistribuição de terras, ocupação de novas áreas, a exemplo do Centro-Norte, da Amazônia e do Nordeste.

Mais que um projeto, a ocupação da Amazônia, segundo os planos do Estado Brasileiro, configurava-se como prioridade na agenda institucional, pois as doutrinas da segurança, da integração nacional, fundamentavam um plano audacioso para explorar os rincões do país. Como parte dessa ação prioritária, tanto as ações dirigidas, sejam pelo Governo ou a iniciativa privada, fundaram diferentes projetos e núcleos de ocupação.

Em Mato Grosso, na porção norte do Estado, a Colonizadora Sinop S.A., cuja sigla corresponde à Sociedade Imobiliária Noroeste do Paraná, dirigida pelos empresários Enio Pipino (1917-1995) e João Pedro Moreira de Carvalho (1910-1995), criou o núcleo colonial Gleba Celeste, a partir do qual as cidades de Vera, em 1972, Sinop e Santa Carmem, em 1974, e Cláudia, em 1978, foram instituídas. Dentre as quatro, Sinop adquiriu posição de destaque, passando a comandar as relações comerciais dentro da área, operando como uma referência às três cidades co-irmãs (TEIXEIRA, 2006).

Com objetivos claramente marcados, o projeto da Colonizadora Sinop para a Gleba Celeste objetivava torná-la apta à produção de alimentos, energia carburante e a partir do etanol de mandioca, fixação do homem na Amazônia e distribuição da riqueza consequentemente na área colonizada.

No dizer de Enio Pipino, mais que um projeto de colonização, instituía-se nova dinâmica migratória no curso de 1970 e agindo sobre o contingente de migrantes brasileiros. "Eu tenho hoje quase que um orgulho pessoal em pensar, assim, nós conseguimos modificar a marcha do homem em busca de novas aventuras. Nós mudamos o roteiro das migrações encaminhando-o para o Norte do Mato Grosso e também para Rondônia [...]” (PIPINO, 1982).

Ao articular um discurso que tornava o projeto da Gleba Celeste uma terra de esperança e na qual se encontravam as soluções aos colonos que enfrentavam dificuldades em seus Estados de origem e precisavam lançar-se em direção às terras desconhecidas, como as da 
Amazônia brasileira, o movimento migratório passou a ser considerado, segundo premissa da empresa privada, uma vanguarda econômica àqueles que apostassem na inicitiva:

No processo de colonização, a companhia exerceu uma influência que não pode ser caracterizada como simplesmente econômica. A colonizadora Sinop colaborou na construção de todo um espaço social e na vida cotidiana dos migrantes, através da ocupação planejada e controlada do espaço geográfico, da construção de um discurso que exalta o trabalho e o desenvolvimento econômico, a ordem e a família (SOUZA, 2006, p. 206).

Para atrair o maior número de pessoas à localidade, as propagandas eram ambiciosas, provocadoras, buscavam incentivar a migração na área. Logo, a Gleba Celeste passou a figurar no centro de práticas discursivas diversas que enfatizavam a ocorrência de um arrojado empreendimento construído no norte-mato-grossense. Os enunciados passam a aparecer de forma concreta em um tempo e espaço historicamente constituídos e mediados pelo dizer do empresário Enio Pipino.

\section{Discurso e verdade na produção de sentidos}

Foucault (2008, p. 122) trata do discurso como "um conjunto de enunciados, na medida em que se apoiem na mesma formação discursiva", estando constituído por "um número limitado de enunciados para os quais podemos definir um conjunto de condições de existência". Isto é, na tessitura desse autor, o enunciado se porta como uma função que atravessa estruturas e unidades possíveis linguisticamente - uma frase ou uma proposição, por exemplo - e faz com que lhes atribuamos (ou não) um sentido e/ou um valor de verdade.

Dessa forma, o conceito de discurso é apresentado como prática. Já a formação discursiva citada pelo filósofo denota a condição de existência desses enunciados e que carregam não apenas sentidos, mas história: "formação discursiva esconde o plano geral das coisas ditas no nível específico dos enunciados" (AZEVEDO, 2013, p. 155). Para Michel Foucault (2008, p. 43), as formações discursivas são responsáveis pelas "condições de existência (mas também de coexistência, de manutenção, de modificação e de desaparecimento) em uma dada repartição discursiva".

Nos estudos sobre o discurso e a produção de verdades, o filósofo questiona esse último conceito, preferindo trabalhá-lo enquanto um estatuto da verdade (FOUCAULT, 2018) que desempenha papeis político, social, institucional, econômico, entre outros. Ou seja, a verdade a que Michel Foucault (2018, p. 53) chama a atenção não expressa o “"conjunto das 
coisas verdadeiras a descobrir ou a fazer aceitar"”, mas o “conjunto das regras segundo as quais se distingue o verdadeiro do falso e se atribui ao verdadeiro efeitos específicos de poder"” (FOUCAULT, 2018, p. 53) e apresentados no/pelo jogo enunciativo.

Conforme Michel Foucault, cada sociedade tem seu regime de verdade, sua " "política geral' de verdade: isto é, os tipos de discurso que ela acolhe e faz funcionar como verdadeiros" (FOUCAULT, 2018, p. 52). Nesta lógica, é possível afirmar que os discursos vão produzir efeitos de verdade que não são nem verdadeiros nem falsos, pois, de acordo com o filósofo, não se quer a verdade escondida, mas como historicamente são produzidos os efeitos de verdade que fazem com que o discurso seja tomado como verdade.

Fabrício (2006, p. 55) expõe que os regimes de verdade da cena focaultiana resultam na produção da "ideia de poder, pois normatizam e normalizam a vida social, legitimando conceitos, crenças, valores e possibilidades de ver, agir e desejar”. Neste cenário, “os sentidos seriam interessados, pois são produzidos por uma trama de forças e condições sóciohistoricamente determinadas" (FABRÍCIO, 2006, p. 55).

Na perspectiva ora discutida, o discurso constrói um "efeito do real" e "efeitos de poder", sendo que esse não se configura de forma estática, mas sócio-historicamente. Tal poder em questão, conforme demonstrou Foucault (2018), não é representado com uma figura/objeto palpável, atingível no sentido físico, mas uma prática construída por instituições sociais que também se utilizam de tal estatuto para produzir suas verdades. Logo, essas também se constroem face às relações de poder, pois tais relações irão reafirmar o estatuto do verdadeiro.

Situando a fala do filósofo ao contexto da pesquisa, é no plano do discurso que se busca legitimar conhecimentos e justificar ações, a exemplo da instituição do projeto de colonização em questão, como estudaremos a seguir.

\section{Práticas discursivas e a relação criador/criatura na Gleba Celeste}

Para Foucault, o discurso e as relações de poder ligam-se mutuamente, uma vez que aquele sempre se produziria em função dessas (FISCHER, 2020). “Tudo está imerso em relações de poder e saber" (FISCHER, 2020, p. 75). Nessa perspectiva, os enunciados “constituem práticas sociais por definição permanentemente presas, amarradas às relações de poder, que as supõem e as atualizam" (FISCHER, 2020, p. 75). 
Ao mesmo tempo, como já alertava o filósofo cujas investigações consideravam a “descrição dos acontecimentos discursivos" (FOUCAULT, 2008, p. 30), não se busca encontrar "a voz silenciosa escondida nas entrelinhas" ou "o que o autor pretendia dizer naquilo que disse", pois não se portam como objeto de análise. Busca-se compreender, então, "[...] por que não poderia ser outro [discurso/enunciado], como exclui qualquer outro [discurso/enunciado], como ocupa, no meio dos outros [discursos/enunciados] e relacionado a eles, um lugar que nenhum outro [discurso/enunciado] poderia ocupar" (FOUCAULT, 2008, p. 31). Em suma, "que singular existência é esta que vem à tona no que se diz e em nenhuma outra parte" (FOUCAULT, 2008, p. 31).

No caso em particular da Gleba Celeste, como apareceram um ou mais enunciados e não outros em seus lugares. Para descrever os acontecimentos do discurso, portanto, os enunciados tornam-se centrais. Para Foucault (2008, p. 98), esse conceito não equivale à unidade enquanto estrutura, mas "uma função de existência que pertence, exclusivamente, aos signos, e a partir da qual se pode decidir, em seguida, pela análise ou pela intuição, se eles 'fazem sentido' ou não [...]".

Essa função, portanto, atravessa estruturas e unidades possíveis linguisticamente uma frase, uma proposição ou um ato de linguagem, como Foucault (2008) propõe - e faz com que lhes atribuamos (ou não) um sentido e/ou um valor de verdade. Na perspectiva teórica desse autor, um enunciado está relacionado com as leis de possibilidade, com as relações que estão aí afirmadas ou negadas, isto é, um "referencial", que justamente define as possibilidades de aparecimento e de delimitação do que dá sentido e possui valor de verdade para as estruturas e unidades linguísticas.

Além de um referencial, todo enunciado também possui um espaço adjacente ocupado por outros enunciados. Outros elementos também caracterizam essa função (enunciado): um “sujeito (no sentido de 'posição' a ser ocupada), um campo associado (isto é, coexistir com outros enunciados) e uma materialidade específica - por tratar de coisas efetivamente ditas, escritas, gravadas em algum tipo de material, possíveis de repetição ou reprodução" (FISCHER, 2020, p. 77) que são ativadas, por exemplo, nas relações sociais.

Na presente investigação, que analisa a constituição discursiva da fundação da Gleba Celeste, o referencial é exercido pela figura do colonizado; o sujeito que afirma algo pelo empresário Enio Pipino; um campo associado que torna um enunciado não isolado de outros enunciados, mas coexistentes; a materialidade traduzida pela maneira como esse enunciado sobre o projeto de colonização aparece em diferentes situações e a partir dos sujeitos. 
Dessa relação emergem as figuras do criador e da criatura no processo de fundação da Gleba Celeste. Denota-se a existência de uma hierarquia na qual a mão do criador surge como um guia à criatura, sem a qual não se caminharia rumo ao progresso e à racionalidade. Em tal perspectiva - que se mostra igualmente dicotômica - o colonizador exerce sua dominação e controle sobre o que se pretende dizer. Ou, igualmente, sobre os efeitos de verdade que se tornarão conhecidos para que funcionem como verdadeiros.

O discurso de Enio Pipino e os sentidos produzidos sobre a Gleba Celeste interpelam o colonizado e, consequentemente, ambos contribuem com o processo de colonização às suas respectivas maneiras. De igual forma, a ênfase sobre este projeto traz à rede sentidos a existência de um sujeito superior (colonizador) e outro inferior (colonizado) que passam a ser recuperados mediante a necessidade de se abordar o projeto.

Onde só havia o nada, dever-se-ia instituir uma civilização; onde a terra era vazia, necessário era seu povoamento por meio da Gleba Celeste. Nos primeiros enunciados de Enio Pipino apresentam-se o trabalho de divulgação e a atração do sujeito migrante.

Enunciado 01: Ali nós fizemos um trabalho de colonização muito grande onde vivem hoje perto de 500 mil pessoas mais ou menos nas áreas colonizadas pela Sinop. É uma dúzia de cidades mais ou menos, até que exauridas todas as possibilidades de colonização nós começamos a sentir e haver uma grande corrida e uma movimentação da criatura humana em direção ao Paraguai, ao norte da Argentina, assolados pelo minifúndio que já então se tornava improdutivo na introdução do maquinário agrícola que se incentivava em todo Brasil.

Enunciado 02: Nós fazemos um trabalho de persuasão muito grande. Nós temos um trabalho que pega aqui do Espírito Santo, Minas Gerais, São Paulo, Paraná, Santa Catarina, Rio Grande do Sul, em todos esses Estados nós temos gente oferecendo terras e oferecendo as condições para que as informações, para que a criatura passe acreditar na Amazônia e hoje já não é novidade.

O retorno ao contexto sócio-histórico de fundação da Gleba Celeste encontra-se entrelaçado nos primeiros enunciados de Enio Pipino, pois todo enunciado supõe outros enunciados. Um enunciado figura, portanto, em um ponto definido, com posição, função e papel determinados, em um jogo enunciativo no qual outros enunciados integram-se para compor o sentido e o valor de verdade.

Como sintetiza Foucault (2008, p. 112), não há enunciado em geral, enunciado livre, "neutro e independente; mas sempre um enunciado fazendo parte de uma série ou de um conjunto, desempenhando um papel no meio dos outros, neles se apoiando e deles se distinguindo", pois, segundo o teórico, ele "se integra sempre em um jogo enunciativo" 
(FOUCAULT, 2008, p. 112). Tratar da Gleba Celeste é, ao mesmo tempo, retornar à experiência da empresa colonizadora em outras regiões do país, anteriormente à expansão dos negócios para Mato Grosso ("até que exauridas todas as possibilidades de colonização").

Com atuação iniciada no Estado do Paraná, onde pelo menos 500 mil pessoas viviam nas áreas colonizadas pela empresa, a Colonizadora Sinop ampliou sua atividade para Mato Grosso. Tal operação não representou um interesse comercial unicamente, mas pela prática discursiva do colonizador foi significada como uma iniciativa capaz de deslocar o fluxo migratório para as terras da Amazônia brasileira. Por isso, a oferta de informações deveria fazer a criatura acreditar em tal mobilização ("oferecendo as condições para que as informações, para que a criatura passe acreditar na Amazônia”.)

Como indica a formulação de Enio Pipino, o sentido de hierarquia - do colonizador sobre o colonizado - é manifestado pela relação entre os sujeitos do processo de colonização: o criador e a criatura. O primeiro mobiliza e justifica a instituição de um espaço e, o segundo, adere à iniciativa. Ao criador compete a missão de realizar campanhas pró-migração fundamentadas na ocupação da terra; às criaturas, exclusivamente, integrarem-se ao processo e dele participar. Embora essencial ao processo, a criatura designada pelo colonizador não possui rosto, sequer nome. É um ser inominado que deveria participar da fundação da Gleba Celeste.

Os sentidos produzidos a partir de dados discursos, por parecerem "reais", produzem "efeito de verdade" (FOUCAULT, 2018). Nesta direção, os enunciados do colonizador fazem funcionar como verdadeira a instância da colonização, da fundação da Gleba Celeste como resposta à inserção do homem em uma nova frente migratória e constroem o efeito de poder. As relações sociais entre colonizador e colonizado, as relações de poder e o próprio estatuto de verdade, no sentido focaultiano do termo, emergem como epicentro de uma transição a partir da qual a realidade passa a ser considerada como um acontecimento discursivo.

Desta maneira, o discurso do empresário constrói um "efeito do real”, "efeitos de poder" e, como tal, os efeitos dessa verdade vão depender diretamente das relações de poder estabelecidas sócio-historicamente. Tome-se como exemplo o colonizador enunciando acerca da fundação da Gleba Celeste e a colonização brasileira. Mediante os regimes de poder, produzem-se discursos que pressupõem efeitos-verdades em relação a essa operação na Amazônia. Diremos, nesse percurso, que por haver em cada sociedade um dado regime de poder/verdade, cada uma defende o discurso que se pretende tornar como o mais verdadeiro. 
[...] a "verdade" é centrada na forma do discurso científico e nas instituições que o produzem; [...] é produzida e transmitida sob o controle, não exclusivo, mas dominante, de alguns grandes aparelhos políticos ou econômicos (universidade, exército, escritura, meios de comunicação); enfim, é objeto de debate político e de confronto social (as lutas "ideológicas)" (FOUCAULT, 2018, p. 52).

Segundo Enio Pipino, o projeto Gleba Celeste possuía como finalidade fixar o migrante, ser um espaço propício à produção agrícola e à industrialização na área colonizada para assegurar a sobrevivência da criatura. O que permitirá a um ou mais enunciados de o empresário situarem-se no decorrer de uma organização e irromper em um dado tempo e espaço é "justamente o fato de eles pertencerem a uma determinada formação discursiva" (FISCHER, 2020, p. 78).

No acontecimento da fundação da Gleba Celeste, a prática discursiva do colonizador filia-se à formação discursiva de base governamental que remonta aos planos de Estado e a estratégia de efetivar “"pólos de desenvolvimento', concentrando investimentos em determinadas regiões, susceptíveis de crescimento planejado, capazes de alavancar regiões vizinhas sob sua influência" (MORENO, 2005, p. 37). Face ao objetivo de fundar a Gleba Celeste a inscrição em uma outra formação discursiva, o enunciado a seguir expõe a finalidade da iniciativa de colonização mato-grossense:

Enunciado 03: Fixação da criatura humana, produção agrícola, industrialização e possibilidade para que nós pudéssemos fazer energia carburante e, também, para possibilitar que estes homens que faziam conosco a mesma aventura encontrassem na Amazônia um meio de sobrevivência e participassem do progresso dessa grande aventura.

A prática discursiva que configura o ambiente da Gleba Celeste materializa sentidos relacionados à ocupação e à fixação do migrante na Amazônia Legal como uma aventura a ser vivida pela criatura, em nome do progresso pretendido para a região. Nesse enunciado, embora a categoria criatura seja substituída por homem, ambas se comportam como sinônimos, não havendo ruptura no efeito de sentido no/pelo dizer empresarial: o colonizador marca sua posição sobre a classificação do referido sujeito.

Pela formação discursiva a qual Enio Pipino inscreve-se é que se determina o que pode e deve ser dito dentro de um determinado campo e em consonância com uma certa posição que nele é ocupada. Trata-se de uma relação que funciona como regra para prescrever aquilo "que deve ser correlacionado em uma prática discursiva, para que esta se refira a tal ou qual objeto, para que empregue tal ou qual enunciação, para que utilize tal conceito, para que 
organize tal ou qual estratégia" (FOUCAULT, 2008, p. 82). Nesta direção, apenas este enunciado poderia ser dito e não outro em seu lugar, uma vez que os sentidos no/pelo dizer de Enio Pipinio relacionam a colonização no norte de Mato Grosso à operação brasileira de ocupar a Amazônia e consolidar a expansão econômica. A inscrição de um discurso em uma outra formação discursiva confere sentidos que marcam esse novo discurso e sua repetição.

A Colonizadora Sinop, enquanto uma instituição personificada pela figura de Enio Pipino, opera na construção e divulgação de discursos e 'verdades' que vão instaurar realidades nas quais seja possível existir e agir. Portanto, por haver em cada sociedade um dado regime de poder/verdade, cada uma defende o discurso que se pretende tornar como o mais verdadeiro. No caso do episódio em estudo, por exemplo, os sentidos sobre a fundação da Gleba Celeste pela ótica do criador que remontam à colonização como um mecanismo de segurança nacional.

Com o status de uma nova terra a ser ocupada, a construção discursiva em torno do projeto o colocou no centro de uma iniciativa para a interpelação de migrantes, estabelecendoo como fecundo ao desenvolvimento. Assim, a ocupação constituiu-se a partir, em especial, de uma série de propagandas e anúncios veiculados pela empresa Colonizadora Sinop tanto nas cidades onde atuava, quanto em rádios, em revistas e em jornais.

E, na tentativa de incentivar a migração na área, a presença desse projeto em publicações da imprensa parecia enfatizar a ocorrência de um arrojado empreendimento construído no norte-mato-grossense. Esses trabalhos midiáticos procuravam elencar o êxito da iniciativa em consonância com o chamamento do Governo Federal para se fazer ocupar as áreas até então ausentes de exploração econômica. Ainda em 1973, quando o primeiro núcleo urbano - Vera - foi criado, notícias referentes a ele já apareciam na agenda da imprensa brasileira (NASCIMENTO, 2018, p. 87-88).

No grupo de migrantes que para a Gleba Celeste se deslocou estavam aqueles oriundos do Sul Brasileiro, de Estados como o Paraná, Rio Grande do Sul e Santa Catarina. Mas o trabalho de divulgação do empreendimento não se resumia a estas unidades federadas e abarcava, igualmente, Minas Gerais e Espírito Santo (NASCIMENTO, 2018). O recrutamento e a seleção observavam os diferentes perfis do público que se idealizada àquela região. No enunciado que se segue, Enio Pipino reafirma a lógica criador/criatura ao passo que seu dizer retorna à formação discursiva de ordem estatal na qual remonta a Amazônia como um espaço vazio, sendo justificável sua ocupação.

Enunciado 04: O homem sai e vai abrir lá na Amazônia. Isto é, também, uma aventura. Isto é uma aventura que eu acho glorificada, eu acho que cada criatura 
daquela devia ser condecorado, porque ele tá prestando pra nação um grande trabalho, o trabalho da ocupação da Amazônia, desse grande espaço vazio (PIPINO, 1982).

Filiar-se à uma formação discursiva significa que o enunciado de Enio Pipino não é isolado. Ao contrário, retoma outros enunciados de forma a resgatar: a) o discurso da ocupação da Amazônia; b) da política de povoamento das áreas vazias; e, c) o discurso da inserção dos sujeitos a partir de projetos colonizatórios. Compete à criatura "ir e abrir a Amazônia", ou, como denota o enunciado, aventurar-se nesta iniciativa e ser condecorado(a) por tal feito. Neste mesmo enunciado, ao abordar os movimentos de "sair e abrir na Amazônia", os sentidos da formulação remetem ao desbravamento dessa região em âmbito político e a consolidação da Gleba Celeste neste marco econômico e político.

Nos enunciados trabalhados até o presente momento, a classificação criador e criatura perfaz o discurso da fundação da Gleba Celeste e produz dissimetrias, oposições que reafirmam a existência de dois grupos em posições distintas, desiguais, marcadas pela hierarquização. Ao ser interpelado pelo discurso do colonizador, o colonizado assume um papel determinado naquele empreendimento. Nasce o "sujeito progressista na Gleba Celeste" (NASCIMENTO; TOMÉ, 2016, p. 30), isto é, um conceito social novo para designar o “indivíduo que ali se dirigia e que apresentava, como característica uma reunião de sentidos, entre eles o esmero ao trabalho [...] a dedicação com a família e com o próximo [...], a alegria de participar deste momento histórico [...]”.

A própria concepção de haver na Gleba Celeste um criador e inúmeras outras criaturas baseia-se na "ideia de que existem espaços, povos e tempos periféricos e, ao mesmo tempo, de que existe um lócus de enunciação legítimo e central” (BRAGATO, 2014, p. 214). Neste aspecto, o espaço é representado pelas terras da Amazônia brasileira, os povos pelas criaturas e o lócus de enunciação como a Gleba Celeste, a partir da qual Enio Pipino manifesta seu dizer. Todo esse processo de produção de efeitos de sentido/verdade é legitimado pela enunciação.

Mais que levar o migrante para a Gleba Celeste, a empresa colonizadora precisava assegurar formas de que ele sobrevivesse na área. As estratégias, então, vislumbravam a criação de uma indústria para a produção de energia carburante, bem como uma cooperativa para incentivar o processo agrícola (NASCIMENTO, 2018; SANTOS, 2011; SOUZA, 2006, 2015). Nos dois últimos enunciados, Enio Pipino afirma a interdependência entre colonização e a criatura, de modo que a sorte de um se ligava ao outro. 
Enunciado 05: [...] a empresa se preocupa com contentamento e com a felicidade da criatura humana porque eles são fatores importantes para que você traga outros e mais outras criaturas, viu? E esse otimismo regional é que possibilita a vinda de outros colonos, a insatisfação interna provocaria sim um revês; quase que assim um expurgo do elemento que tivesse vontade de se fixar na Amazônia.

Enunciado 06: Daí a razão porque nós nos preocupamos sempre porque a nossa sorte estava ligada a sorte também do sucesso agrícola dessas criaturas, e daí porque nós nos preocupamos e nos cercamos de todos esses fatores de segurança para que o homem pudesse produzir, criar e poder também fazer com que ele pudesse cumprir as suas obrigações

No enunciado 05, Enio Pipino retoma a perspectiva do desenvolvimento econômico na área como forma de proporcionar 'a felicidade da criatura humana'. Uma vez assegurando tal sentimento, a própria criatura, interpelada pelo discurso da empresa e os sentidos por ele produzidos, exerceria sua contribuição na proposta de colonização, isto é, "fatores importantes para que você traga outros e mais outras criaturas". Isto porque, conforme expõe Foucault (2018, p. 52) em uma referência ao discurso e a produção dos regimes de verdade, "os tipos de discurso que ela [sociedade] acolhe" faz "funcionar como verdadeiros". Ou ainda, parafraseando o filósofo, o tipo de discurso que o colonizado acolhe os faz funcionar como verdadeiros.

O estatuto "daqueles que têm o encargo de dizer o que funciona como verdadeiro" (FOUCAULT, 2018, p. 52), por exemplo o colonizador, faz circularem discursos para serem tomados como verdade para o colonizado.

Na rede de sentidos produzidos nos/pelos dizeres de Enio Pipino a preocupação do colonizador quanto à permanência e a sobrevivência da criatura na área colonizada é manifestada pelo desejo de assegurar mecanismos para a sobrevivência do grupo de residentes da Gleba Celeste ("a nossa sorte estava ligada à sorte também do sucesso agrícola dessas criaturas"). Nesta formulação, o Eu (colonizador) assume para si a responsabilidade em proporcionar ao Outro (criatura) as condições de permanência em uma lógica de coexistência projeto empresarial/sujeito migrante.

Faz-se referência às ações comerciais na área para proporcionar a industrialização, desenvolvimento de atividades agrícolas, logística e demais. Somente pelas mãos do criador e o que ela oferta é que a criatura poderia sobreviver, estando esse morador imerso e ao mesmo tempo identificado aos efeitos de sentidos advindos do discurso do colonizador. Nos sentidos produzidos pelo dizer do colonizador, a instrumentalização de mecanismos para promover a fixação da criatura na área da Gleba Celeste também acentua a ótica das relações de poder que reafirmam o estatuto da verdade no/pelo discurso. 
Isso pressupõe um percurso sócio-histórico de fundação e estabelecimento da Gleba Celeste a partir de 'verdades' colocadas em circulação e em conformidade com o regime da época, a partir da posição do colonizador (criador) e o papel político e econômico por ele desempenhado à ocasião.

\section{Mais que cidades}

Neste artigo, observamos como o discurso do colonizador Enio Pipino significou a Gleba Celeste, em Mato Grosso. Ao mesmo tempo em que atuou na produção de efeitos de verdade sobre o empreendimento em um determinado período e espaço, o dizer do empresário paulista reafirmava a existência das categorias criador/criatura que se relacionavam intrinsicamente à iniciativa empresarial. O trabalho foi emoldurado pela teoria de Michel Foucault, com especial atenção à importância do regime discursivo, dos efeitos de poder, dos efeitos de verdade.

No campo das análises, recorreu-se à entrevista concedida por Enio Pipino ao Museu da Imagem e do Som, de São Paulo, no ano de 1982, a partir da qual o episódio de fundação e estabelecimento da Gleba Celeste no Norte de Mato Grosso é recuperado.

A partir do trajeto percorrido, apontou-se para a compreensão de que a abertura da Gleba Celeste é tratada não apenas como uma estratégia administrativa para a criação de cidades, mas uma lógica que hierarquiza, gera poder e discursos. Os esforços dessa colonização parecem pressupor a busca pela verdade a outros [a criatura], corroborando para o advento de uma episteme - a do colonizador-, que é acionada a partir da inscrição de um discurso em outro discurso. A partir da formação discursiva na qual se inserem o colonizador e o colonizado, um ou mais discursos são produzidos e efeitos, por parecerem reais, têm efeito de verdade (FOUCAULT, 2018).

A partir de então, emergem os padrões dicotômicos como 'o que está do lado de lá/de cá', 'este em detrimento daquele', o 'criador e a criatura' e que vão demonstrar adesão aos efeitos de verdade produzidos sobre o projeto de colonização norte-mato-grossense. À luz dos enunciados observados, as figuras do criador e da criatura são constantemente retomadas quando da menção à Gleba Celeste e sua criação. Para produzir sentidos sobre o projeto, inicialmente, faz-se necessário relacionar as figuras envolvidas no processo e que se 
inscrevem em uma formação discursiva, recuperam sentidos que os interpelam e, consequentemente, favorecem ao processo de colonização da região.

\section{REFERÊNCIAS}

ARRUDA, Zuleika Alves. Sinop: território(s) de múltiplas e incompletas reflexões. 1997. 183 f. Dissertação (Mestrado em Geografia)-Universidade Federal de Pernambuco, Pernambuco, 1997.

AZEVEDO, S. D. R. Formação discursiva e discurso em Michel Foucault. Revista Eletrônica de Pesquisa na Graduação em Filosofia da UNESP - FILOGÊNESE, v. 6(2), p. 148-162, 2013.

BRAGATO, Fernanda Frizzo. Para além do discurso eurocêntrico dos direitos humanos: contribuições da descolonialidade. Revista Novos Estudos Jurídicos - Eletrônica, v. 19, n. 01, p. 201-230, jan-abri. 2014.

BRASIL. Lei $n^{\circ}$ 5.173, de 27 de outubro de 1966. Dispõe sobre o Plano de Valorização Econômica da Amazônia; extingue a Superintendência do Plano de Valorização Econômica da Amazônia (SPVEA), cria a Superintendência do Desenvolvimento da Amazônia (SUDAM), e dá outras providências. Presidência da República, Casa Civil. Disponível em: < https://www.planalto.gov.br/ccivil_03/leis/15173.htm>. Acesso em: 30 maio. 2020

BRASIL. Decreto-Lei no 1.106, de 16 de junho de 1970. Cria o Programa de Integração Nacional, altera a legislação do impôsto de renda das pessoas jurídicas na parte referente a incentivos fiscais e dá outras providências. Presidência da República, Casa Civil. Disponível em: <http://www.planalto.gov.br/ccivil_03/decreto-lei/1965-1988/Del1106.htm>. Acesso em: 30 maio. 2020.

BRASIL. Lei $n^{\circ}$ 5.727, de 4 de novembro de 1971. Dispõe sobre o Primeiro Plano Nacional de Desenvolvimento (PND), para o período de 1972 a 1974. Presidência da República, Casa Civil. Disponível em: < https://www.planalto.gov.br/ccivil_03/leis/1970-1979/15727.htm>. Acesso em: 30 maio. 2020.

BRASIL. Lei ${ }^{\circ}$ 6.151, de 4 de dezembro de 1974. Dispõe sobre o Segundo Plano Nacional de Desenvolvimento (PND), para o período de 1975 a 1979. Diário Oficial [da] República Federativa do Brasil, Brasília, DF, 05 dez. 1974. Disponível em:

<http://www.planalto.gov.br/ccivil_03/leis/1970-1979/L6151.htm>. Acesso em: 22 maio. 2020.

FABRÍCIO, Branca Falabella. Linguística Aplicada como espaço de “desaprendizagem”: redescrições em curso. In: MOITA-LOPES, Luiz Paulo da (Org.). Por uma linguística aplicada indisciplinar. São Paulo: Parábola, 2006. p. 45-65.

FISCHER, Rosa Maria Bueno. Sobre discursos e a análise enunciativa. In: FISCHER, Rosa Maria Bueno. Trabalhar com Foucault: arqueologia de uma paixão. Autêntica Editora, 2020, p. 73-96.

FOUCAULT, M. A arqueologia do saber. Rio de Janeiro: Forense-Universitária, 2008. 
FOUCAULT, Michel. Verdade e poder. In: FOUCAULT, Michel. Microfísica do Poder. São Paulo: Edições Graal, 2018. p. 35-54.

MORENO, Gislaene. Políticas e estratégias de ocupação. In: MORENO, Gislaene; HIGA, Tereza Cristina Souza (Org.). Geografia de Mato Grosso: território, sociedade, ambiente. Cuiabá: Entrelinhas, 2005. cap. 3. p. 34-51.

NASCIMENTO, Leandro José do; TOMÉ, Cristinne Leus. A construção da imagem do sinopense como um sujeito de progresso nas páginas de "O Sinopeano" número 15, de 1980. In: XIV Colóquio Nacional de Estudos Linguísticos e Literários, 2016, Sinop. Anais eletrônicos...Sinop: Unemat, 2016. p. 23-32.

NASCIMENTO, Leandro José do. (Re)ler o impresso Jornal Hoje: o discurso da construção de uma terra de progresso e oportunidade em Sinop-Mato Grosso. 2018. 255 f. Dissertação (Mestrado em Letras)-Programa de Pós-graduação em Letras, Universidade do Estado de Mato Grosso, Sinop, Mato Grosso, 2018.

PIPINO, Enio. Enio Pipino: entrevista. [01 julh. 1982] Entrevistadores: José Carlos Pereira de Freitas, Bacilla Neto. São Paulo, SP, 1982. Gravação digital de áudio (53:13). Entrevista concedida ao Projeto Memória da Amazônia do Museu da Imagem e do Som.

ROHDEN, Josiane Brolo. A reinvenção da escola: história, memórias e práticas educativas no período colonizatório de Sinop - MT (1983-1979). Dissertação (Mestrado em Educação). UFMT: Universidade Federal de Mato Grosso, Instituto de Educação, Programa de Pósgraduação em Educação. 2012.

SANTOS, Luiz Erardi F. Raízes da História de Sinop. Sinop: Midiograf, 2011.

SOUZA, Edison Antônio de. Sinop: História, Imagens e Relatos. Um estudo sobre a sua Colonização. Cuiabá: EdUFMT/FAPEMAT, 2006.

SOUZA, Edison Antônio de. Sinop: Espaço e Memória. In: DIAS, Marieta Prata Lima; PHILIPPSEN, Neusa Inês; STRAUB, Sandra Luzia Wrobel; PIBOMBO-OLIVEIRA, Tânia. Amazônia: visão caleidoscópica. Recife: Pipa Comunicação, 2015, p. 121-145.

TEIXEIRA, Luciana. A colonização no norte de Mato Grosso: o exemplo da Gleba Celeste. 2006. 116 f. Dissertação (Mestrado em Geografia). UNESP: Universidade Estadual Paulista, Faculdade de Ciências e Tecnologia.

Recebido em 29/05/2020. Aceito em 31/08/2020. 